\title{
Remote Sensing Mapping of Cyanobacteria Blooms in Chaohu based on Spatio- Temporal-Spectrum Fusion: Improvement on Spatial Scales
}

\author{
Yawen $\mathrm{Hu}^{1,2^{*}}$ and $\mathrm{Li} \mathrm{Li}^{3}$ \\ ${ }^{1}$ College of Resource and Environment Science, Wuhan University, Wuhan 430079, China \\ ${ }^{2}$ Yangtze River Water Resources Commission, Wuhan 430010, China \\ ${ }^{3}$ School of Urban Design, Wuhan University, Wuhan 430072, China
}

Received 13 September 2019; Accepted 29 November 2019

\begin{abstract}
Occurrence and relevant risks of cyanobacteria blooms have been increasing continuously in the world wide. Monitoring on spatial and temporal distribution changes of cyanobacteria blooms has been the key of environmental monitoring. In particular, spatio-temporal distribution of cyanobacteria blooms in complicated small inland water areas changes so frequently and a more accurate inversion monitoring method and product was required with the fact that quality of inversion results of existing major optical remote sensing monitoring means is determined by the source images. Due to mutual restraints of temporal, spatial and spectral resolution of satellite images, common multispectral images cannot realize high-accuracy monitoring in complicated small inland water areas. A method to improve inversion accuracy and spatial resolution of inversion products was carried out in this study. Based on multisource image data, inversion models of chlorophyll a (Chl-a) and cyanobacterial biomarker pigment phycocyanin (PC) concentration in Lake Chaohu were constructed with the image fusion algorithm and machine learning algorithm. Effects of increasing spatial scale of source image on inversion accuracy were verified by comparing accuracy of the inversion models based on fusion image and original moderate-resolution imaging spectroradiometer (MODIS) images in the same period under the same conditions. Moreover, inversion mapping with high accuracy and high spatial scale was accomplished for several days successively. Results demonstrate that accuracy of the inversion model be increased with improving spatial resolution of source images, which further increased spatial scale of inversion products significantly. This study provides a feasible and effective method to realize high-accuracy monitoring of cyanobacteria blooms in small-scaled but complicated inland water environment.
\end{abstract}

Keywords: Remote sensing, PC, Chl-a, Image fusion, Random Forest

\section{Introduction}

Fresh water resources are closely related with production and daily life of human. Lake and reservoir are main water sources in inland China. Nevertheless, water quality in lakes and reservoirs declines significantly in the past decades and $1 / 3$ reservoirs in China are suffering eutrophication day by day [1]. Cyanobacteria blooms happen successively, which threatens the drinking water source and water ecological environment, and causes inestimable losses [2]. Compared with traditional field sampling and laboratory water analysis method, optical remote sensing satellite data become the first choice for monitoring over cyanobacteria blooms due to the high frequency, large scale and easy availability [3].

In fact, the complicated spatial-temporal characteristics of algal blooms during monitoring based on remote sensing mean restrict selection of satellite image source for inversion. Currently, Landsat images with a spatial resolution of $30 \mathrm{~m}$ in Landsat Thematic mapper (TM) /enhanced thematic mapper (ETM+), MODIS and medium resolution imaging spectrometer (MERIS) images which are used in most studies of water environment based on remote sensing mean are inapplicable to inversion monitoring of cyanobacteria

*E-mail address: huyawenmar@gmail.com

ISSN: 1791-2377 @ 2019 School of Science, IHU. All rights reserved.

doi:10.25103/jestr.126.23 blooms, because of the poor spectral resolution and 16-day revisiting period. The MERIS images with a spatial resolution of $300 \mathrm{~m} / 1200 \mathrm{~m}$ and 3-day revisiting period were stopped running in 2012 and cannot meet requirements for current environmental monitoring. In contrast, MODIS images with a spatial resolution of $250 \mathrm{~m} / 500 \mathrm{~m} / 1000 \mathrm{~m}$ and 1-day revisiting period were more applicable to inversion monitoring of algal blooms. Nevertheless, inversion products based on coarse resolution images (e.g. MODIS) cannot reflect spatial-temporal distribution of algal blooms in small-sized inland water areas accurately. Moreover, the inland water environment is complicate and the spatial heterogeneity of coarse resolution images also may decrease inversion accuracy. Hence, single-source hyperspectral images with coarse resolution are inapplicable to monitor small-scaled algal blooms.

On this basis, existing studies on inversion of concentration of cyanobacteria blooms were reviewed $[4,5]$. Currently, accuracy and spatial scale of major inversion methods are determined by source images involved in the inversion. With considerations to high requirements of water inversion on spectral resolution and mutual restraints of spatial, temporal and spectral resolutions of remote sensing images, it is difficult to increase inversion accuracy and spatial scale of inversion products by using single-source coarse resolution images. Therefore, how to increase spatial 
scale of inversion products by using existing multispectral images and decrease influences of spatial heterogeneity of complicated water environment on inversion accuracy is a problem that has to be solved urgently.

\section{State of Art}

Studies on monitoring inland water mainly focus on middle and small-sized water areas. Under this circumstance, spatial scale of images is the main factor that influences inversion results.

Scholars have reviewed abundant existing studies on spatial scale and accuracy of water inversion. Some major problems were summarized as follows: (1) for middle and small-sized water areas, coarse resolution images like MODIS data could cover the whole water area by dozens of pixels [6], thus resulting in very large inversion monitoring error of cyanobacteria blooms [7]. High-resolution images like Landsat data fail to meet monitoring needs due to the poor spectral and temporal resolutions. (2) Floating algal plaques might be smaller than single pixel of images, which bring estimation errors of algal bloom concentration [8]. In addition, spatial heterogeneity of water surface caused by the complicated water environment and spatial scale effect in remote sensing inversion of water quality properties caused by spatial heterogeneity could further influence inversion monitoring based on coarse resolution images [9].

Under this circumstance, spatial resolution $(500 \mathrm{~m})$ of MODIS images could not meet requirements of higher accuracy in inland water monitoring. Bonansea et al. tried to estimate water quality directly by using multi-time phase and high-spatial resolution Landsat images [10]. Although they could gain high spatial scale, temporal and spectral resolutions of Landsat satellite images were inapplicable to the changing and complicated inland water environment [11] When studying influences of spatial scale, $\mathrm{Hu}$ et al. pointed out that estimation accuracy of algal bloom concentration was influenced significantly by hybrid pixel images containing algae on water surface [12], moreover, they proposed a linear pixel non-hybrid algorithm to improve estimation accuracy of algal coverage in Lake Taihu. Shanmugam et al. estimated algal coverage on sea surface below the hybrid pixels by using similar algorithms [13]. However, this algorithm was still restricted by low spatial resolution. On this basis, Zhang et al. proposed a pixel growth algorithm to improve the possible scale effect of coarse resolution images by increasing spatial resolution of inversion products [14], and Qi et al improved this algorithm to increase the inversion accuracy greatly [15]. In this study, spatial scale of images was improved from the perspective of source images directly by using image fusion method.

In addition, there are abundant research fruits to improve inversion of chlorophyll concentration or concentration of cyanobacteria blooms based on MODIS Terra/Aqua data. Various models and algorithms from the simplest empirical regression model [16] to semi-analysis model based on chlorophyll concentration [17], from the edition analysis algorithm of Chl-a [18] to the three-waveband model [4] and waveband ratio model [14], even to indexes (e.g. normalized difference vegetation index (NDVI), enhanced vegetation index (EVI), floating algae index (FAI), PC and baseline normalized difference bloom index (BNDBI) related with Chl-a and PC concentrations, all devoted to increase the inversion accuracy [19-22]. Due to setting of spectral bands of images, PC index that can represent phycocyanobilin cells is only applicable to MERIS images. Indexes like NDVI, EVI are very sensitive to characteristics of aerosol and sun lights. Hence, inversion accuracy of models based on these indexes was influenced significantly by different environmental factors [23-25]. By contrast, FAI which involves near-infrared and middle-infrared bands can adapt to various environments better. Existing indexes and multisource images are influenced by environmental changes. Therefore, Fang et al. tried to improve accuracy of multisource inversion based on mutual complementation of different data sources [26]. Liang et al. constructed a decision-making tree by using FAI, turbidity water body index (TWI) to increase extraction accuracy of algal blooms [27]. The method to increase monitoring accuracy of cyanobacteria blooms based on cooperation of multisource data has achieved good effects.

Above studies mainly focus on improvement of spatial scale and accuracy of water inversion, but rare studies have improved accuracy of inversion products directly. In this study, inversion accuracy of cyanobacteria blooms and spatial resolution of inversion products were increased in order to realize high spatial-temporal resolution and highaccuracy inversion of small inland water areas. Here, multisource remote sensing images were integrated by spatial-temporal-spectrum fusion algorithm, thus acquiring continuous fusion images with both high spatial and high spectral resolution. It increased spatial resolution of inversion products and decrease error of scale effect under coarse resolution from the perspective of image source. Later, accuracy of the inversion model was increased by a multi-index collaborative model. This study is to propose a convenient and accurate quantitative inversion mapping technique of cyanobacteria blooms to accomplish highaccuracy continuous inversion monitoring in complicated small-scaled water environment.

The rest of this study is organized as follows. Section 3 establishes the Spatial-Temporal-Spectral fusion model and proposes the method for improving inversion accuracy and spatial resolution of inversion products Section 4 discusses the comparison of inversion results. Section 5 summarizes the conclusions.

\section{Methodology}

\subsection{Study area}

Lake Chaohu (east longitude $117^{\circ} 24^{\prime}-117^{\circ} 90^{\prime}$ north latitude $31^{\circ} 40^{\prime}-31^{\circ} 72^{\prime}$ ) is one of five largest freshwater lakes in China. The water depth $0.98 \sim 7.98 \mathrm{~m}$ and the water area was $760 \mathrm{~km}^{2}$. The region where Lake Chaohu locates in has about 150 rainy days in one year and about 210 drought days [28]. Lake Chaohu was famous for its beautiful scenes and relevant economic activities like the fishing prosperity before 1960s [29]. Surrounding cities of Lake Chaohu achieved quick population growth and rapid economic development in recent decades. Various types of wastewater rich of organic nitrogen and phosphorus expose lakes to eutrophication, thus resulting in frequent occurrence of cyanobacteria blooms [30,31]. Such situation of Lake Chaohu has attracted key attentions of lake monitoring and governance in China in recent years. 


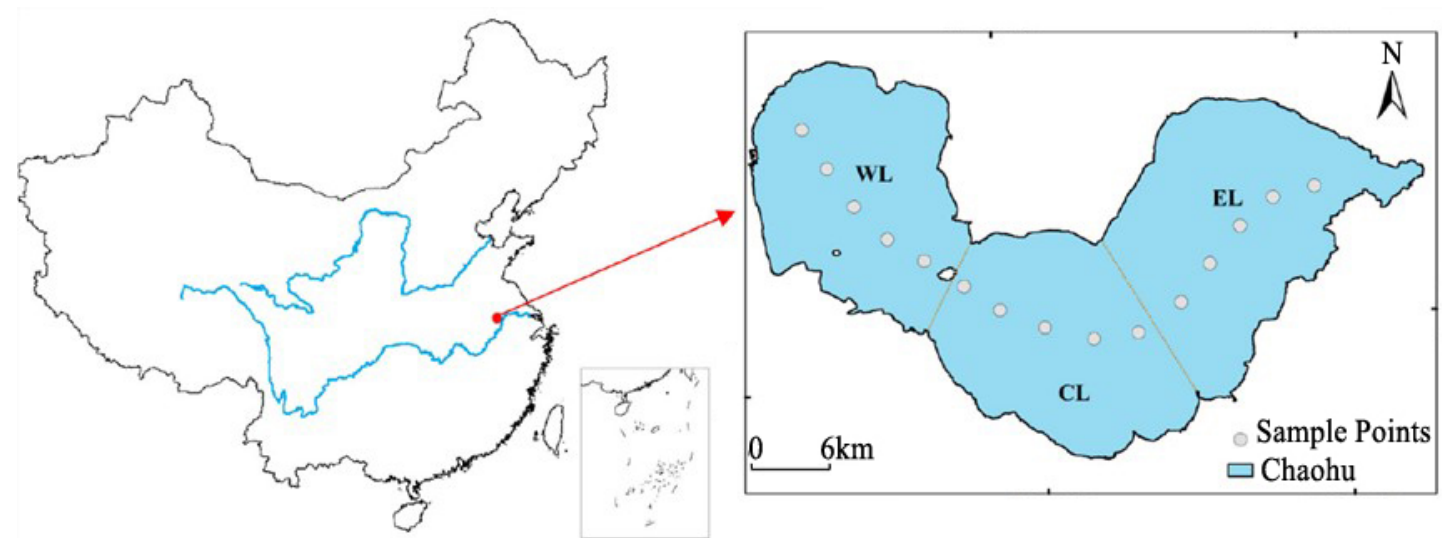

Fig. 1. Location and distribution map of Lake Chaohu, China. And the distribution of 15 sample points adopted.

\subsection{Data}

\subsubsection{Field data}

Distribution of field sampling points of water quality data in Lake Chaohu is shown in Fig.1. In each sampling process, samples were collected from 15 points which were distributed evenly in west, middle and east regions of the Lake Chaohu. This assures the comprehensive and uniform data about water quality in the Lake Chaohu. Samples were collected on January and April, 2015 as well as December, 2016 , respectively. A total of 45 samples were collected.
Sample data mainly concentrated in winter and spring when cyanobacteria blooms in the Lake Chaohu were in the dormancy. Water samples were all collected by a standard $2 \mathrm{~L}$ polyethylene collecting instrument from water surface (about $30 \mathrm{~cm}$ depth). Water quality parameters were tested by a standard test mean in laboratory.

PC used the standards of Sigma Company as the reference and it was tested by a spectrophotometer (Shimadzu RF-5301, 620nm excitation and 647nm emission). Chl-a was measured by the spectrophotometry recommended by NASA [32].

Table 1. Water quality properties collected in Lake Chaohu. Chl-a: chlorophyll-a; PC: Cyanobacteria phycocyanin pigments

\begin{tabular}{c|c|c|c|c|c|c|c}
\hline \multirow{2}{*}{ Data } & \multirow{2}{*}{$\mathbf{N}$} & \multicolumn{2}{|c|}{ Chl-a $(\boldsymbol{\mu g} / \mathbf{L})$} & \multicolumn{2}{c|}{ PC $(\boldsymbol{\mu g} / \mathbf{L})$} & \multicolumn{2}{c}{ PC : Chl-a } \\
\cline { 3 - 8 } & & Mean & Range & Mean & Range & Mean & Range \\
\hline 20150117 & 15 & 57.96 & $22.44-138.55$ & 51.31 & $9.85-321.27$ & 1.02 & $0.1-4.11$ \\
20150414 & 15 & 22.37 & $6.85-85.87$ & 31.46 & $8.88-113.33$ & 1.51 & $0.53-2.31$ \\
20161207 & 15 & 26.13 & $6.78-54.53$ & 67.38 & $9.85-136.93$ & 5.33 & $0.19-20.3$ \\
\hline
\end{tabular}

\subsubsection{Image data}

In this study, satellite surface reflectivity product which was downloaded free from NASA was applied and 90-scene images were collected in three months, including surface reflectivity data (MOD09GA) and surface temperature data (LST). Temporal images with heavy cloud coverage in the study area were eliminated after preprocessing, thus getting continuous daily MODIS images. Besides, three scenes of ETM with high spatial resolution (20150120, 20150426 and 20161208) without cloud coverage in the corresponding periods and images were downloaded as the fusion reference images. Detailed information of the corresponding sensor is shown in Fig.2.

Table 2. Information of Satellite sensor

\begin{tabular}{c|c|c|c|c|c}
\hline Satellite & Sensor & Spatial resolution / m & Revisit cycle / d & Band & Spectrum \\
\hline Terra & MODIS & $250 / 500 / 1000$ & 1 & 16 & $405-2155$ \\
Landsat-7 & ETM+ & 30 & 16 & 7 & $450-2350$ \\
\hline
\end{tabular}

\subsection{Spatial-Temporal-Spectral Fusion Model}

Due to influences of signal-to-noise ratio (SNR) of images, data storage and transmission, optical diffraction limit, single-source remote sensing images cannot possess satisfying spatial, spectral and temporal resolutions due to mutual restraints [34]. In practical applications, inversion of water quality properties has high requirements on spectral resolution and it is only applicable to single-source remote sensing images for inversion of water quality properties. This inversion mapping has high inversion accuracy, but the
Since spectrum is based on MODIS images after image fusion, image wavebands were selected according to spectral setting characteristics of MODIS images.

Due to the complicate atmospheric and water environments in Lake Chaohu, the marine waveband of MODIS images may be saturated and it was omitted in this study. Dynamic ranges covered by wavebands $(645 \mathrm{~nm}$ and $859 \mathrm{~nm}$ ) of the $250 \mathrm{~m}$ MODIS images and wavebands $(469 \mathrm{~nm}, 555 \mathrm{~nm}$ and $1240 \mathrm{~nm})$ of 500m MODIS images were higher than that of marine wavebands, it was hardly to have saturation phenomenon in turbid water areas [33].

Moreover, the wavelength was applicable to calculation of parameters in the selected model. In this study, five were chosen as the research wavebands.

spatial resolution of inversion products is generally very low. Moreover, the temporal resolution at continuous monitoring cannot meet requirements completely. This may represent very great disadvantages in continuous monitoring of complicated small-scaled inland water areas. Hence, multisource images were applied and supplemented to increase the inversion accuracy [23]. wavebands of $469 \mathrm{~nm}, 555 \mathrm{~nm}, 645 \mathrm{~nm}, 859 \mathrm{~nm}$ and $1240 \mathrm{~nm}$ 


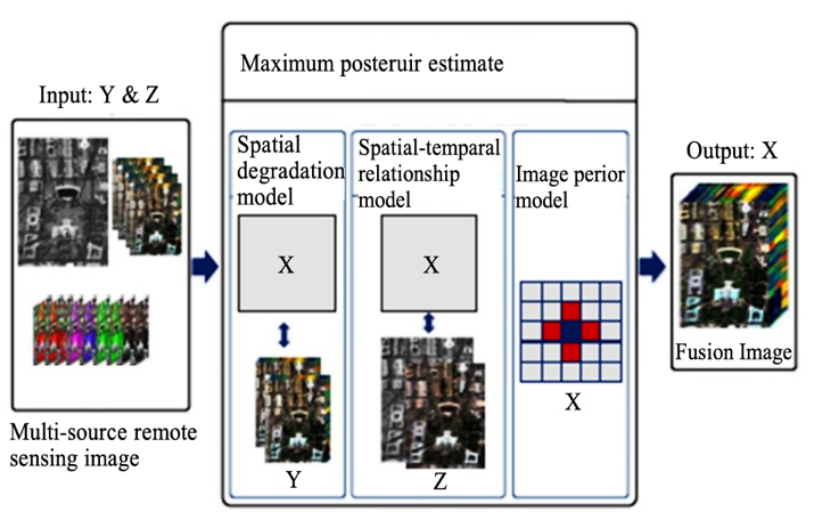

Fig. 2. Frame of Spatial-Temporal-Spectral fusion model.

Spatial-temporal-spectral fusion model can make complementary advantages of spatial, spectral and temporal information of multisource remote sensing images and the fusion images with high spatial-temporal-spectral resolution can meet high requirements on image resolutions [35]. This fusion model is constructed based on the Bayes maximum posterior probability theoretical framework. The basic framework is shown in Fig.2. Y is the spatial degradation observation images with low spatial resolution, but high spectral and temporal resolutions. In the laboratory, MODIS images were used as the reference images. $\mathrm{Z}$ is images with high spatial resolution, but low spectral and temporal resolutions. In the laboratory, ETM + images were used as the reference.

In the present study, two sensors were integrated. The image fusion process is shown in Fig.3. ETM+ images $(30 \mathrm{~m})$ of Time A and MODIS surface reflectivity images $(500 \mathrm{~m})$ were used as the reference images. Sequence of wavebands of MODIS images has to be adjusted to form a mapping relation of spectral setting with ETM+ image spectral setting and spectral range. MODIS surface reflectivity images of Time B which is close to Time A are input and fused to get fusion images with high spatial and spectral resolutions at Time B. Finally, spectra of MODSI reflectivity image at Time B were used as benchmark for residual calibration of spectra of fusion images, thus getting fusion images at Time $\mathrm{B}$. The revisiting period of MODIS is one day. Theoretically, continuous fusion images with high spatial and spectral resolutions in 3 months could be gained as the source image data for the follow-up modeling and inversion. Theoretical spatial resolution of fusion images can reach the standard of $\mathrm{ETM}+$, which is $30 \mathrm{~m}$. After residual calibration of spectra, spectra of fusion images were same with those of MODIS images.

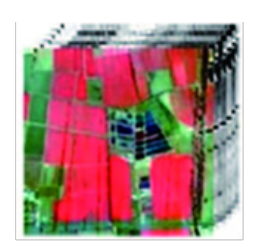

Time A ETM+

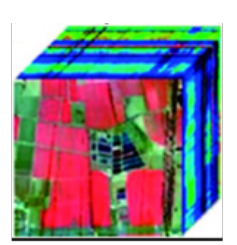

Time A Modis

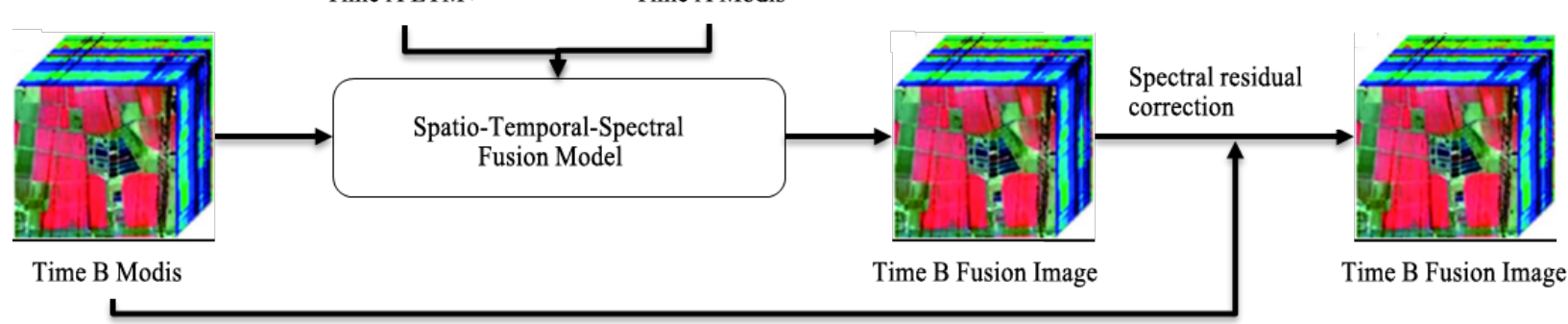

Fig. 3. Image fusion processing flow in this experiment with Spatial-Temporal-Spectral fusion model

\subsection{Index for the model}

At massive reproduction and clustering of cyanobacteria blooms on water surface, the water body may present spectral characteristics similar with vegetation. For MODIS surface reflectivity data, NDVI can distinguish floating algae from surrounding water environment. However, it is sensitive to changes of conditions, such as water environment and aerosol. In quantitative analysis, these conditional changes not only can influence visual contrast and the absolute value of NDVI may have errors [31]. The calculation formula of NDVI is shown in Eq.(1), where RED and NIR are surface reflectivity at $645 \mathrm{~nm}$ and $859 \mathrm{~nm}$ wavebands of MODIS.

$$
N D V I=(N I R-R E D) /(N I R+R E D)
$$

To offset high sensitivity of NDVI to environmental changes, another parameter FAI was applied. FAI mainly reflects differences close to $859 \mathrm{~nm}$ of spectrum between cyanobacteria blooms and surrounding water bodies [36,37]. FAI can avoid possible influences of atmospheric calibration and CDOM disturbance in the blue and green wavebands by using infrared and near-infrared wavebands, so it is influenced less by environmental conditions. The calculation formula of FAI is shown in Eq.(2), where $R_{\text {NIR }}, R_{R E D}$ and $R_{\text {SWIR }}$ are surface reflectivity at $645 \mathrm{~nm}, 859 \mathrm{~nm}$ and $1240 \mathrm{~nm}$ wavebands of fusion images. $R_{\text {NIR }}, R_{R E D}$ and $R_{\text {SWIR }}$ are central values of spectra of corresponding wavebands.

$$
\begin{aligned}
& F A I=R_{N I R}-R_{N I R}^{\prime} \\
& R_{N I R}^{\prime}=R_{R E D}+\left(R_{S W I R}-R_{R E D}\right) *\left(\lambda_{\text {NIR }}-\lambda_{R E D}\right) /\left(\lambda_{\text {SWIR }}-\lambda_{R E D}\right)
\end{aligned}
$$

The parameter BNDBI was introduced in for inversion estimation of Chl-a [20]. It distinguishes chlorophyll and surrounding water environment based on spectral difference at $555 \mathrm{~nm}$ and $645 \mathrm{~nm}$. Besides, it is corrected based on spectra at $469 \mathrm{~nm}$ and $859 \mathrm{~nm}$. With the assistance of BNDBI, the Chl-a can be extracted accurately and possible influences of complicated water environment and atmospheric factors can be weakened. Due to strong correlation between Chl-a 
and Cyanobacteria concentration, BNDBI can be added in for collaborative modeling. The calculation formulas of BNDBI are shown in Eq.(4) (8), where $R_{469}, R_{555}, B_{645}$ and $B_{859}$ are surface reflectivity at $469 \mathrm{~nm}, 555 \mathrm{~nm}, 645 \mathrm{~nm}$ and $859 \mathrm{~nm}$ of fusion images.

$$
\begin{aligned}
& B N D B I=\left(R_{555}^{\prime}-R_{645}^{\prime}\right) /\left(R_{555}^{\prime}+R_{645}^{\prime}\right) \\
& R_{555}^{\prime}=R_{555}-B_{555} \\
& R_{645}^{\prime}=R_{645}-B_{645} \\
& B_{555}=R_{469} * \frac{859-555}{859-469}+R_{859} * \frac{555-469}{859-469} \\
& B_{645}=R_{469} * \frac{859-645}{859-469}+R_{859} * \frac{645-469}{859-469}
\end{aligned}
$$

In addition, water temperature can influence temporal and spatial distribution of Cyanobacteria and chlorophyll significantly [38]. In the present study, LST data gained from data processing of MOD01 are chosen as one of model parameters. The preprocessed surface temperature data collection instrument was applied to extract water surface temperature according to longitude and latitude coordinates after re-sampling and temperature calculation. The extracted water surface temperature was applied for modeling and inversion.

Due to high correlation between Chl-a and PC concentration as well as advantages and disadvantages of different indexes, four parameters including NDVI, FAI, BNDBI and water temperature as well as the random forest model were applied. Based on cooperation and mutual complementation of multi-indexes, this study aims to realize inversion mapping more accurately.

\subsection{Algorithm Approach}

In the present study, multisource image fusion was employed to improve quality of image data. The multi-index collaborative model realizes mutual complementation to reduce environmental factors. The random forest algorithm set up a nonlinear model to increase accuracy of inversion model, finally realizing the goal of accurate inversion mapping with high-spatial-temporal-spectral resolution.

Image processing, modeling and inversion processes are shown in Fig.4. Three major steps were included: (1) Spatial-temporal matching and geometric calibrations of multisource images are implemented. ETM+ images without cloud coverage, but high imaging quality and MODIS images in the same period were used as reference. Continuous fusion images with high spatial and spectral resolutions in three months can be collected by using the spatial-temporal-spectral fusion model and residual error calibration of spectrum. (2) Parameters of fusion images were calculated to get normalized difference vegetation index (NDVI), floating algae index (FAI) image products. Through denoising and re-sampling of LST data, the same spatial resolution of fusion images could be gained. Besides, it got pixel values of corresponding coordinates of NDVI, FAI and land surface temperature (LST) data according to longitude and latitude coordinates of sampling points. A total of 45 groups of model training samples were acquired and abnormal values of sample data were deleted, leaving 43 groups of sample data for modeling. (3) Sample data were trained by the random forest model and accuracy of the model was verified by 10 -fold crossing algorithm. (4) The inversion model with satisfying accuracy was applied for inversion mapping of continuous images in 3 months, thus getting daily continuous inversion products of Chl-a and Cyanobacteria concentration with high spatial resolution (30m).

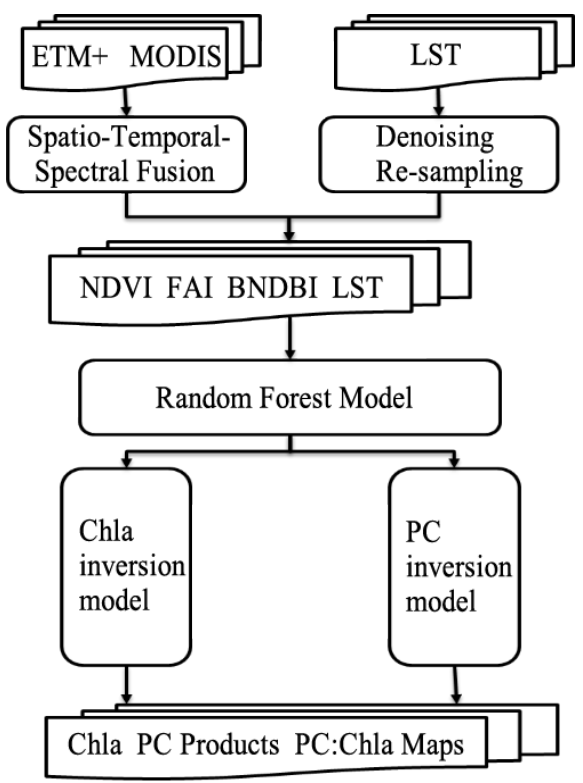

Fig. 4. The processing procedure of Chl-a and $\mathrm{PC}$ inversion products and PC:Chl-a maps.

\subsection{Chl-a and PC products}

Dissolving secreta from growth of Cyanobacteria in water source may cause chronic toxicity of human and thereby cause water pollution. PC was calculated by inversion product of Chl-a concentration and PC concentration: Chl-a gets the Cyanobacteria risk spectrum to estimate proportions of Cyanobacteria in aquatic organism cluster, based on which the degree of water pollution by Cyanobacteria is estimated [39]. Such mapping method is originated from the estimation of water pollution risks [40] by World Health Organization (WHO) based on Cyanobacteria concentration (or equal chlorophyll concentration). However, the actual biomass of Cyanobacteria and total biomass of floating plants cannot be distinguished by single concentration [41]. In the present study, PC Chl-a was applied to reflect relative proportions of total biomass of Cyanobacteria and floating plants in cyanobacteria blooms [42].

\subsection{Algorithm Evaluation}

The accuracy of inversion model was evaluated by three indexes, namely, root-mean-square error (RMSE), mean absolute error (MAE) and $R^{2}$. The calculation formulas of these indexes are shown in Eq.(9) (11), where $Y_{i}$ is the real value, $\hat{Y}_{i}$ is the predicted value of model and $\bar{Y}_{i}$ is average of predicted value.

RMSE is used to measure error between the predicted value and real value. MAE evaluates advantages and disadvantages of model fitting by comparing the assessment values. $\mathrm{R}^{2}$ compares the predicted value with the situation when only mean is used only. If $\mathrm{R}^{2}$ is close to 1 , all predicted values are closer to real results. 


$$
\begin{aligned}
& \text { RMSE }=\sqrt{\frac{\sum_{n}^{i=1}\left(Y_{i}-\hat{Y}_{i}\right)^{2}}{n}} \\
& M A E=\frac{\sum_{n}^{i=1}\left|Y_{i}-\hat{Y}_{i}\right|}{n} \\
& R^{2}=1-\frac{\sum_{n}^{i=1}\left(Y_{i}-\hat{Y}_{i}\right)^{2}}{\sum_{n}^{i=1}\left(Y_{i}-\bar{Y}_{i}\right)^{2}}
\end{aligned}
$$

\section{Result Analysis and Discussion}

\subsection{Inversion model accuracy evaluation}

In this experiment, parameters of MODIS images $(500 \mathrm{~m})$ before fusion and parameters of fusion images $(30 \mathrm{~m})$ at the same time were extracted based on longitude and latitude coordinates of sampling points to verify possible error of spatial scale in quantitative remote sensing inversion of water quality properties [9] and influences of hybrid pixels on inversion accuracy in complicated water environment under low spatial resolution. Both MODIS images and fusion images constructed inversion models of Chl-a and PC concentrations based on the random forest algorithm. Under the same external conditions, accuracies of the constructed inversion models before and after image fusion were compared to prove that increasing spatial resolution can improve the inversion accuracy.

Inversion model of Chl-a concentration uses 45 groups of image extraction data and data collected at stations as the training samples and its accuracy is verified by 10 -fold crossing verification. Relations between predicted values of the inversion model of Chl-a concentration and real values are shown in Fig.5(a) and Fig.5(b). It can be seen from the scatter diagram that inversion accuracy of Chl-a concentration of images after fusion is higher than that of

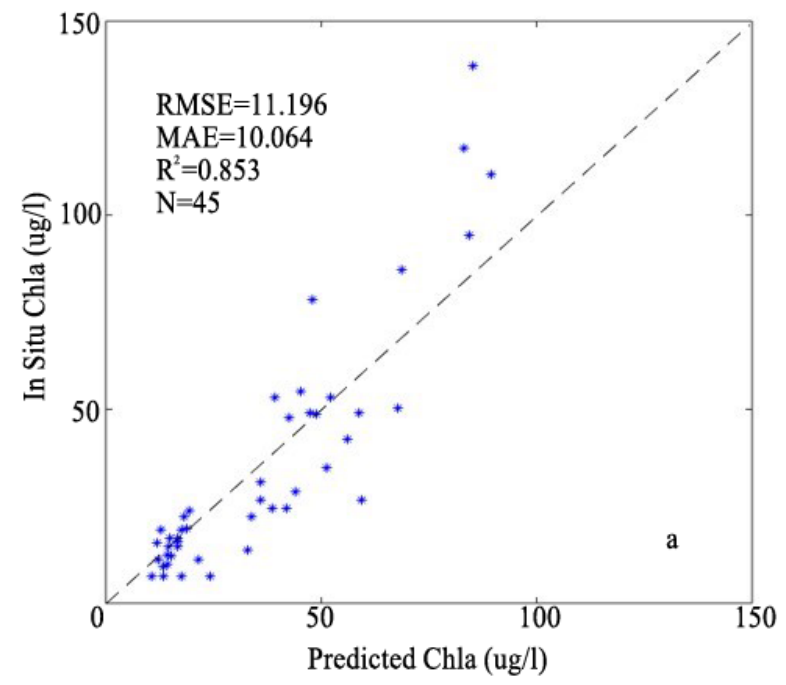

Fig. 5(a). Inversion model validations: Chl-a validation of fusion image;
MODIS image in the same period. For the inversion model based on fusion images, $R^{2}=0.8534$, RMSE $=11.1962$ and $\mathrm{MAE}=10.0643$. For inversion model of Chl-a concentration based on MODIS images, $R^{2}=0.8011$, RMSE $=14.7963$ and $\mathrm{MAE}=11.6538$. Scattering points in Fig.5(a) mainly concentrate close to the line 1:1. Accuracy of the inversion model is improved significantly due to the increase of spatial scale.

After 3 groups of abnormal data are deleted, the inversion model of PC concentration applies 42 groups of data as the training sample and its accuracy is verified by 10 -fold crossing validation. Relations between predicted values of the inversion model of PC concentration and real values are shown in Fig.5(c) and Fig.5(d). For the inversion model based on original MODIS images, $R^{2}=0.8031$, $\mathrm{RMSE}=19.7970$ and $\mathrm{MAE}=16.3346$. For the inversion model based on fusion images under the same conditions, $R^{2}=0.8378, \quad \mathrm{RMSE}=11.9916$ and $\mathrm{MAE}=11.3893$. The inversion model based on fusion images has the higher accuracy.

Inversion of water quality parameters requires high spectral resolution of images. Therefore, influences of hybrid pixels brought by low spatial-scale in the complicated inland water environment on inversion accuracy and poor performance of inversion product with low spatial resolution to small-scaled inland water environment are problems that have to be solved urgently. Here, the comparison on accuracy of inversion models before and after image fusion confirms that error caused by hybrid pixels in coarse resolution images can be decreased by increasing spatial scale. In other words, inversion accuracy of water quality properties can be improved effectively by increasing spatial scale.

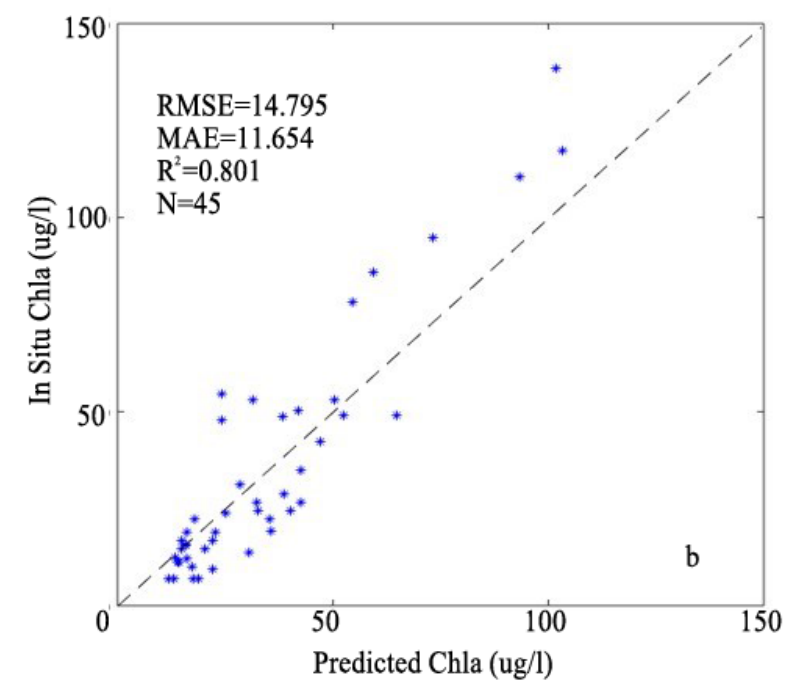

Fig. 5(b). Chl-a validation of MODIS. 


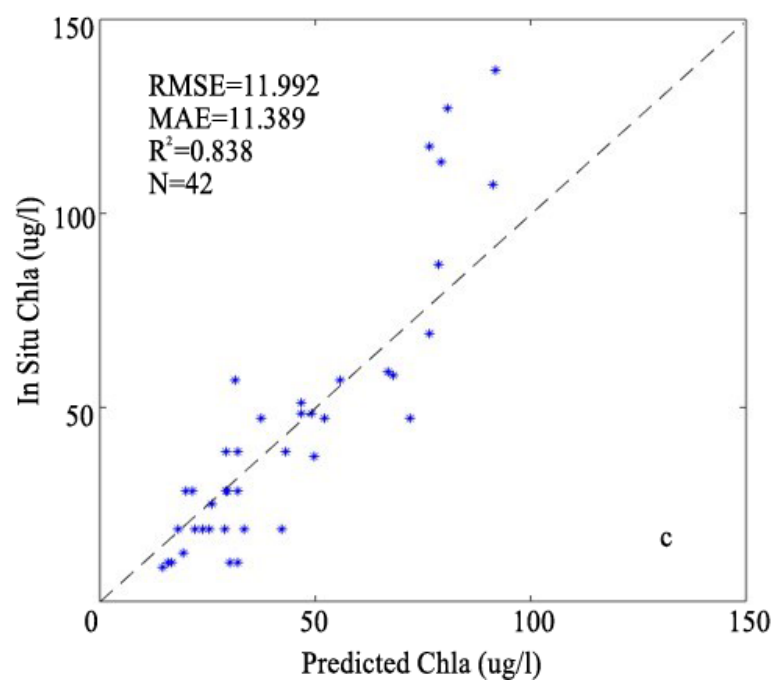

Fig. 5(c). Inversion model validations: PC validation of fusion image;

\subsection{Comparison of inversion results}

\subsubsection{Comparison of chlorophyll a inversion results}

Whether more details in a complicated environment can be observed by eyes and whether more effective information, including spatial-temporal distribution and variation trend of Chl-a, can be gained are determined by spatial resolution of inversion mapping product in a small-scaled water area. In this experiment, models of MODIS images $(500 \mathrm{~m})$ and fusion images $(30 \mathrm{~m})$ were constructed under the same conditions, respectively. Subsequently, inversion and mapping were performed successively. Inversion results of Chl-a concentration on Lake Chaohu on December 7th, 2016 are shown in Fig.6. The left and right pictures in Fig.6 are inversion results of Chl-a concentration based on fusion image and MODIS image on the same day. According to

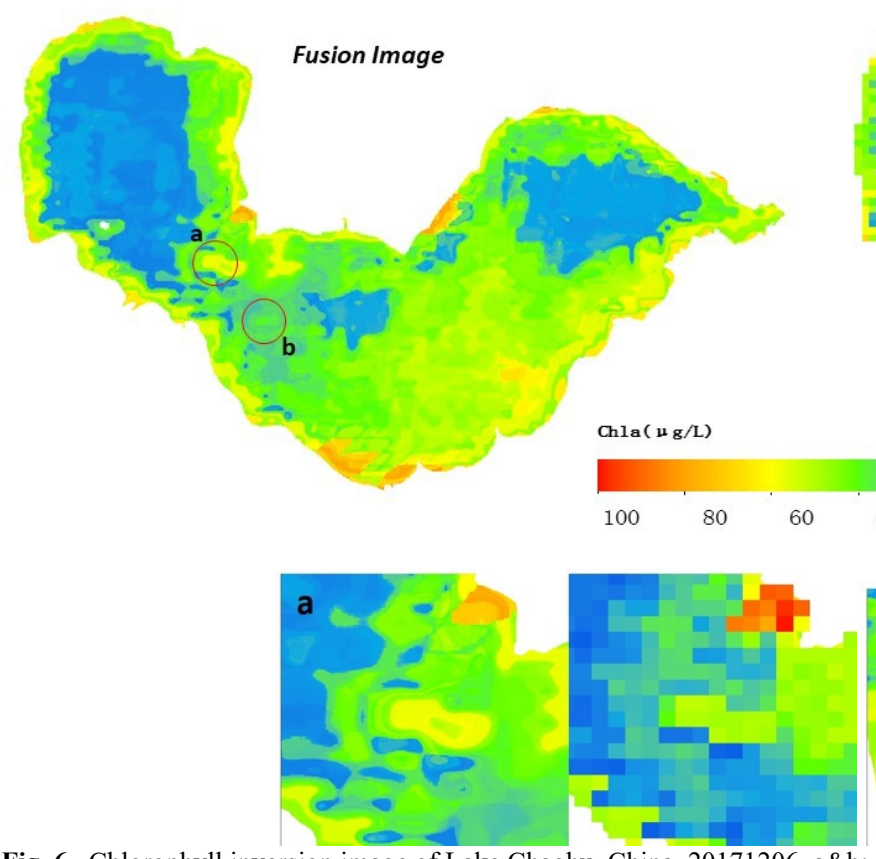

Fig. 6. Chlorophyll inversion image of Lake Chaohu, China, 20171206. a\&b: partial enlargement pictures.(Left: Fusion image product; Right: MODIS image product)

\subsubsection{Comparison of $\mathrm{PC}$ inversion results}

Same with inversion model of Chl-a concentration, inversion results of PC concentration in Lake Chaohu on December

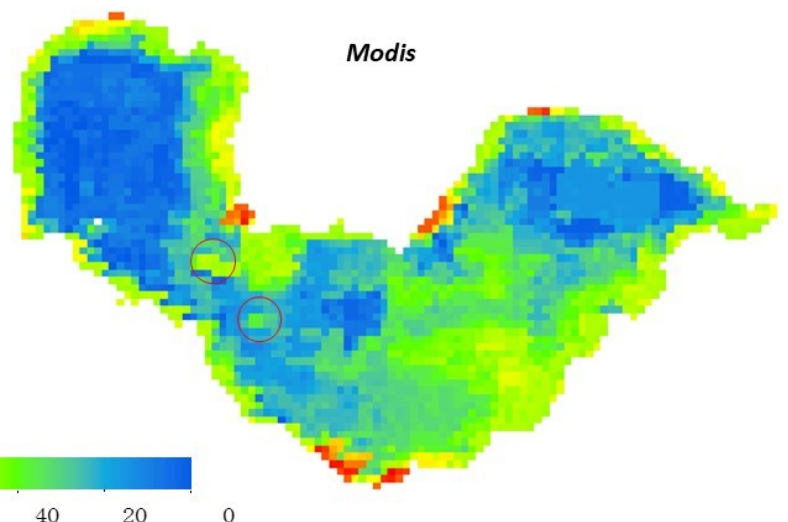

0

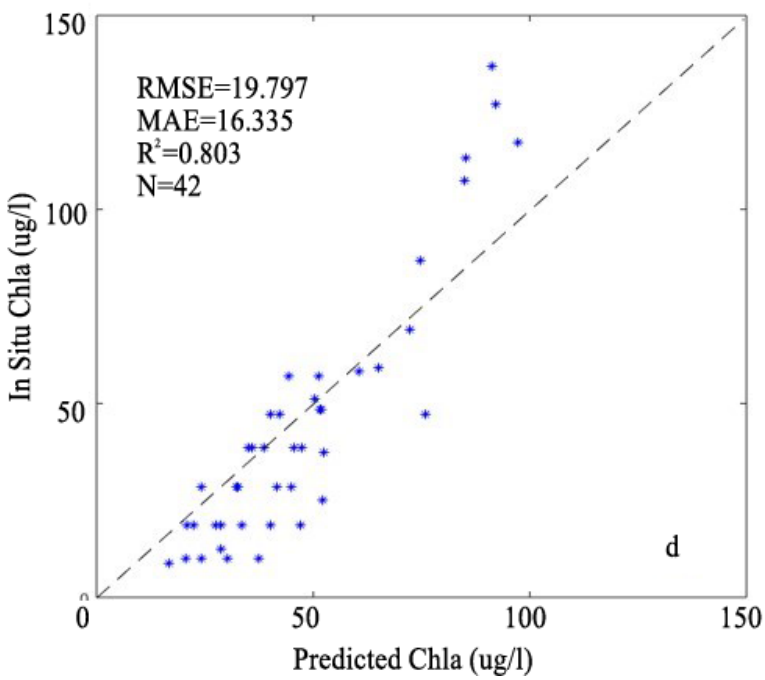

Fig. 5(d). PC validation of MODIS

comparison of two pictures, the spatial distributions of Chl-a concentration are basically consistent, but it is still very easy to see hierarchical distribution and clustering points of Chl-a on fusion images. This is difficult to be realized on MODIS images.

Partial enlargements of fusion image production and MODIS image product in regions a and $b$ were compared. In Fig.6(a), it can be seen from hierarchical distribution and high-concentration region of Chl-a clearly from the fusion image product. However, only several pixel substitutions and a high-concentration region can be observed from the partial enlargement of MODIS product. Similarly, it can be seen from Fig.6(b) that the Chl-a distribution pattern of only few pixel resolution on MODIS image product can be distinguished clearly from fusion image product.

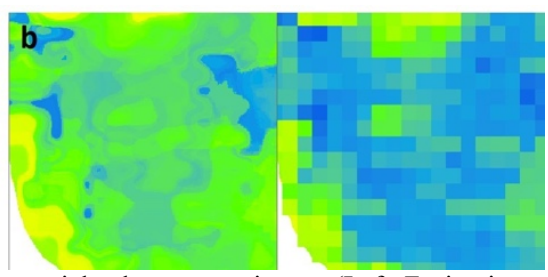

7th, 2016 are compared (Fig.7). The left is inversion results of PC concentration based on fusion images, and the right is inversion results of $\mathrm{PC}$ concentration based on MODIS 
image of the same day. Generally speaking, spatial distribution of PC concentration reflected by both fusion image and MODIS image is basically consistent. However, MODIS image inversion product gives a strong sense of pixels. Specific information similar with fusion image product and hierarchical distribution of concentration cannot be observed.

Similarly, regions $\mathrm{a}$ and $\mathrm{b}$ are enlarged. It can be seen from Fig.7(a) that the high-concentration distribution patterns in fusion image and MODIS image are consistent.
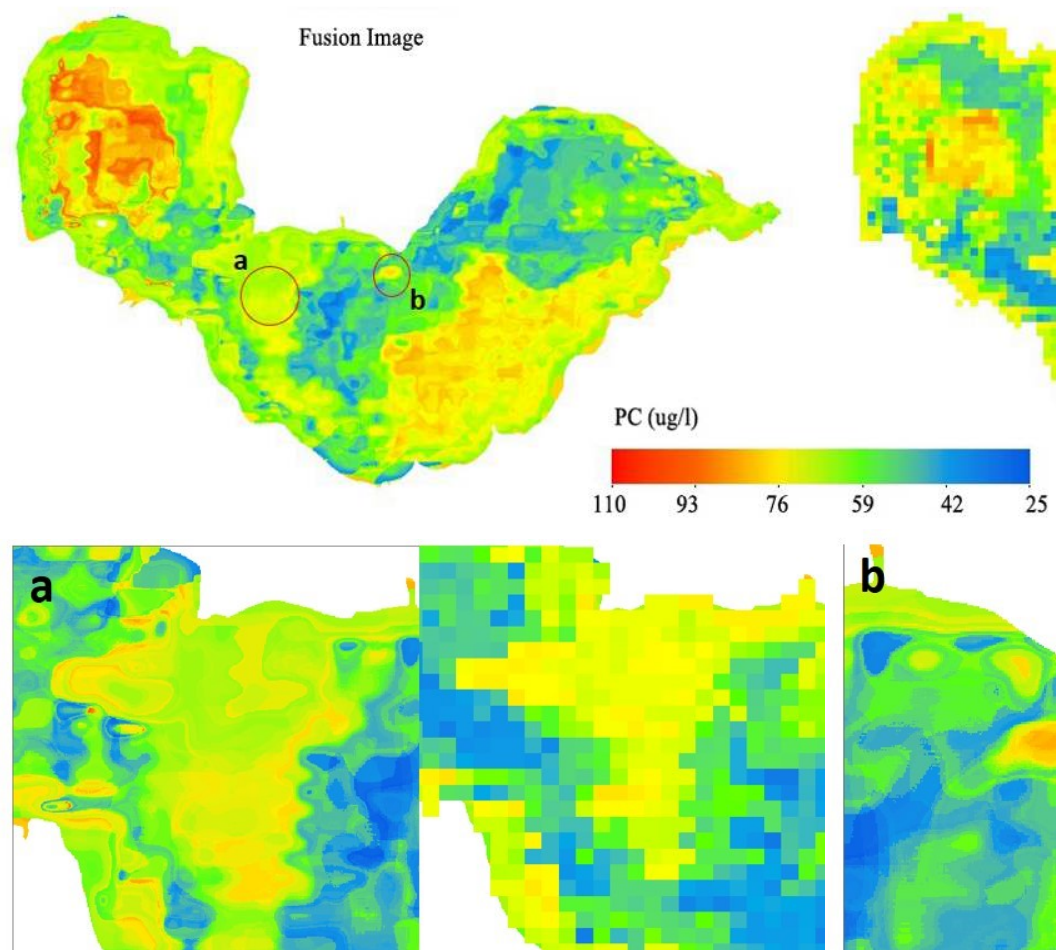

Modis

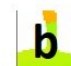
product)

Nevertheless, there's distinct hierarchical distribution of concentrations in fusion image product, but only few pixels are seen from the MODIS image product. In Fig.7(b), regions $a$ and $b$ as well as the range of reducing surrounding concentration are clear in fusion image product. Spatial distribution of only 2-4 pixels can be seen relatively clearly from the MODIS image product.

The spatial-temporal-spectral fusion model and image fusion technique can realize high-accuracy inversion mapping of a complicated small-scaled water environment, including improving accuracy of the inversion model or improving quality of inversion products intuitively. Moreover, quality of inversion mapping product is improved directly by increasing the spatial resolution of images from the perspective of image sources.

\subsection{Temporal and Spatial Changes of Continuous Monitoring of Chl-a}

This study targeted at high-accuracy inversion monitoring of spatial-temporal changes of water bodies in several successive days based on image fusion algorithm. It has been proved by previous experiments that the spatialtemporal-spectral fusion can improve accuracy of the inversion model and spatial scale of inversion products significantly. However, remote sensing images can only be acquired on sunny days, because quality of these images is very sensitive to atmospheric environment (cloud coverage).
Therefore, it is impossible to realize complete successive monitoring in several days in practical applications.

The inversion mapping results in 11 successive days on cloudless days on December, 2016 are shown in Fig.8. Statistical mean Chl-a concentrations in west, middle and east regions of Lake Chaohu in inversion products of uniform extraction concentration according to coordinates of sampling points were calculated. On this basis, the variation curves of daily average Chl-a, daily PC concentration, PC:Chl-a ratio and daily water temperature in three regions of Lake Chaohu were gained.

Based on inversion maps and variation curves of Chl-a concentration, it finds that Chl-a mainly concentrated in coastal regions of east and west regions of the Lake Chaohu in the beginning of December. This is because east and west regions of the Lake Chaohu have dense distribution of urban areas and there's a great number of waste water discharged into the Lake Chaohu through tributaries throughout a year, which would produce abundant aquatic organisms. These are main causes of algal blooms in the Lake Chaohu. From December 2nd to 8th, Chl-a diffused from the east to the west and the overall concentration dropped to $19.9 \mu \mathrm{g} / \mathrm{L}$ on December 8th. This is because many aquatic organisms dived into deep water due to environmental influences and then Chl-a clusters toward the west region of Chaohu Lake. Two clusters were formed after December 15th. 


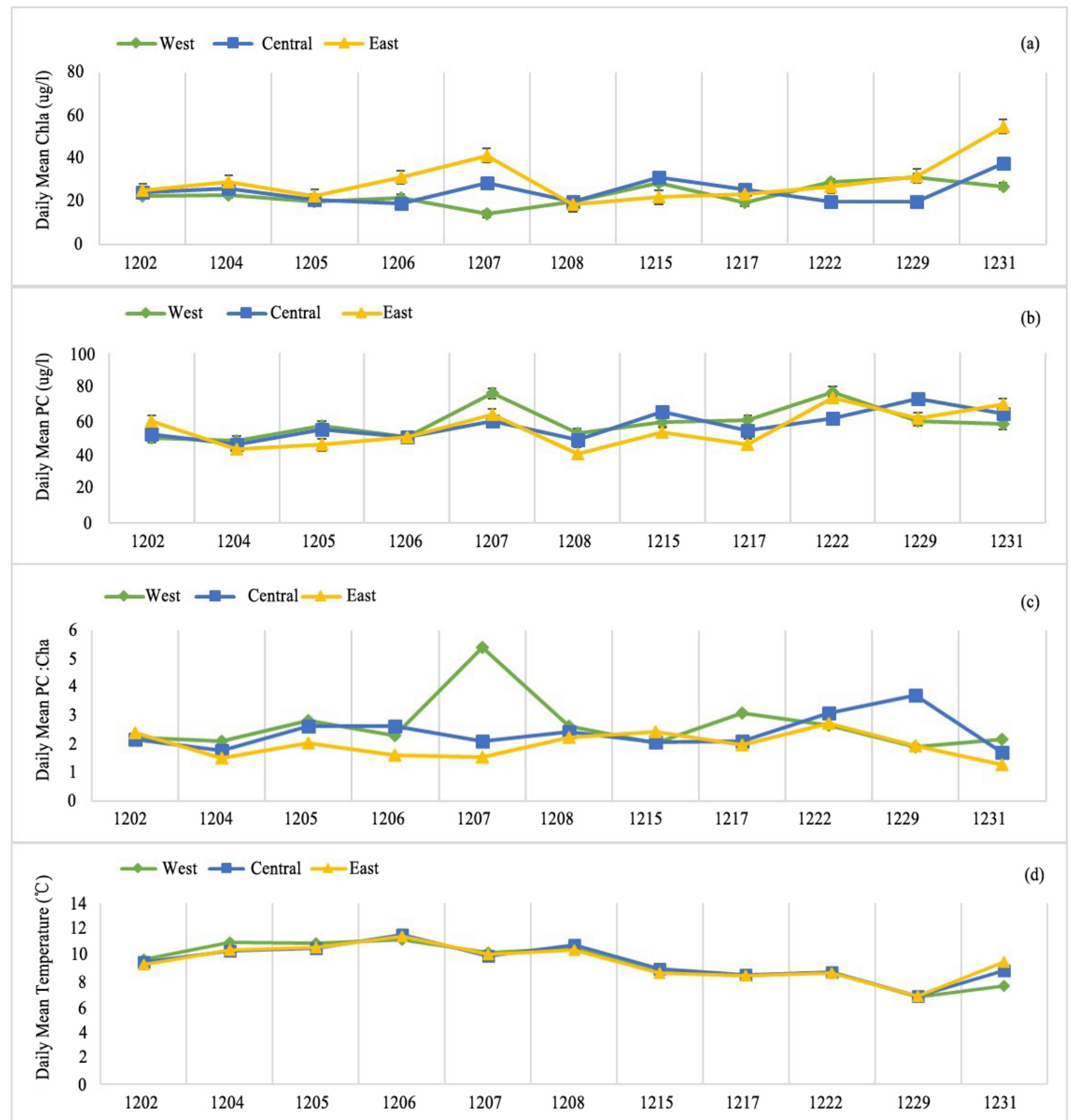

Fig. 8. Daily mean of (a) Chl-a; (b) PC; (c) PC: Chl-a; (d) Temperature.

One cluster diffused from middle to the east region, and the other part concentrated in the west coastal region. The water temperature in three regions of the Lake Chaohu changed slightly on December and water temperature increased significantly at the end of month. Chl-a concentration in three regions also increased significantly, indicating that water temperature is an important influencing factor of spatial distribution. The variation trend of Chl-a concentration in three regions of Lake Chaohu is generally consistent. However, the daily average Chl-a concentration in the east region is the highest $(18.469 \mu \mathrm{g} / \mathrm{L}-55.064 \mu \mathrm{g} / \mathrm{L})$. The daily average Chl-a concentrations in middle $(19.817 \mu \mathrm{g} / \mathrm{L}-37.727 \mu \mathrm{g} / \mathrm{L})$ and west regions $(14.149 \mu \mathrm{g} / \mathrm{L}-$ $31.346 \mu \mathrm{g} / \mathrm{L})$ are close, and Chl-a concentrations in two regions transfer mutually continuously. The inland water environment is complicated and sensitive to environmental changes, resulting in great fluctuations of spatial-temporal distribution.

\subsection{Temporal and Spatial Changes of Continuous} Monitoring of PC

The variation trend of $\mathrm{PC}$ concentration and the variation trend of Chl-a concentration are generally consistent by combining continuous inversion results of $\mathrm{PC}$ concentration on December, 2016 (Fig.9) and variations of daily average PC concentration (Fig.7(b)). PC migrated from the east to the west regions on the first ten-day period of December, and concentrated in the southwest coastal regions. Subsequently, one part diffused from the west to the east and finally reached a uniform distribution, whereas the other part concentrated in southwest coastal regions. 

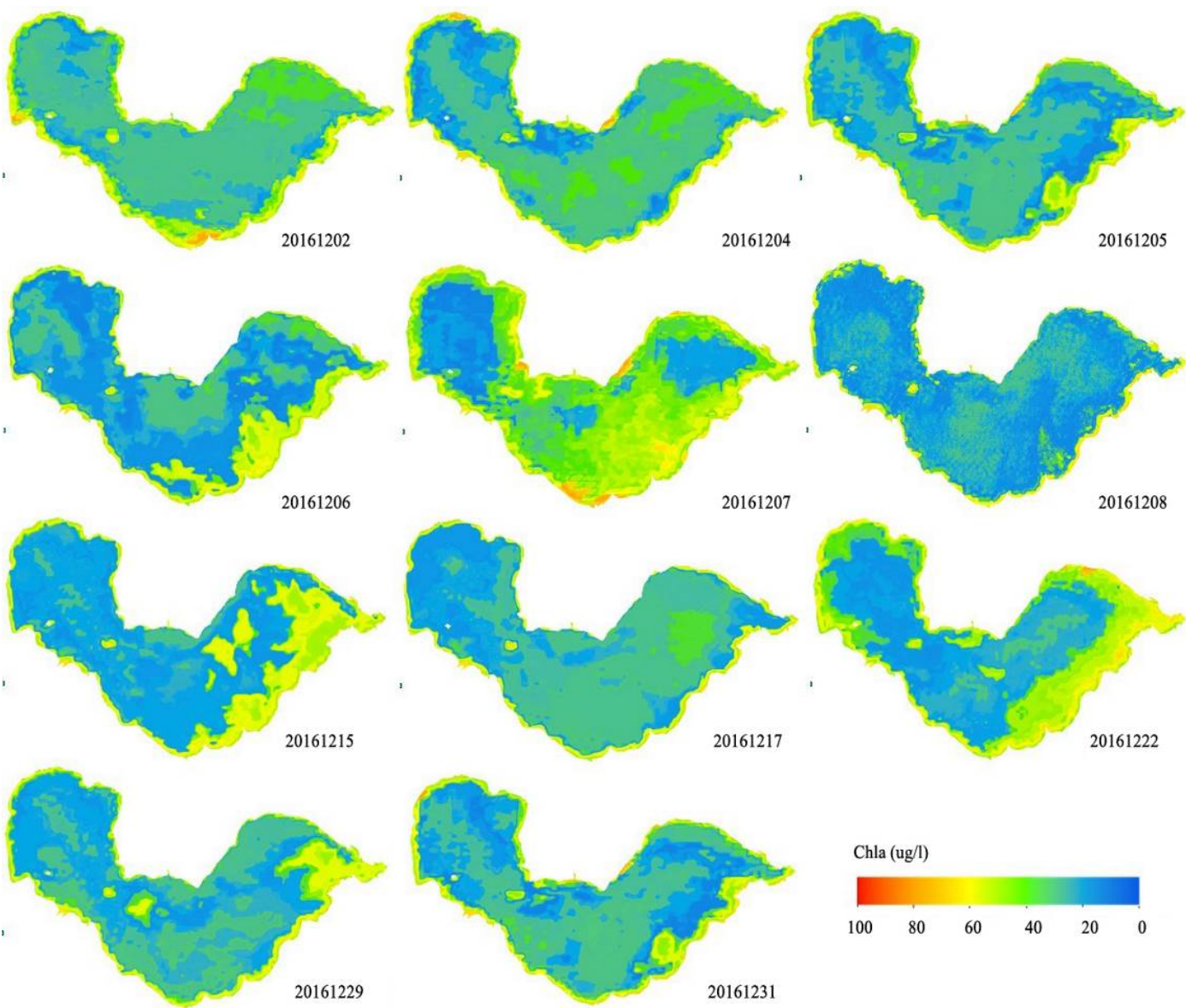

Fig.9. Daily continuous Chlorophyll inversion images of Chaohu ,201612.
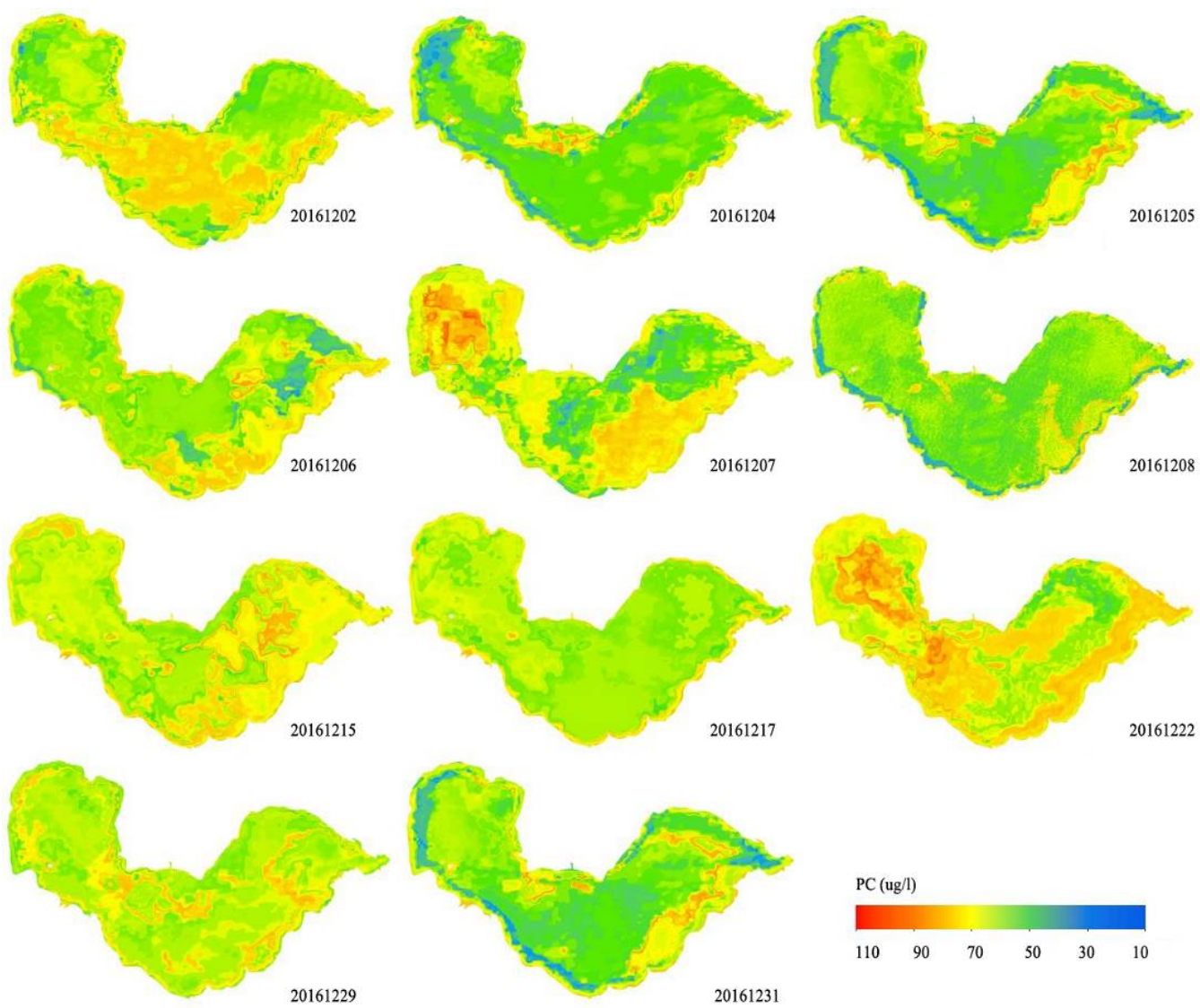

Fig. 10. Daily continuous PC inversion images of Chaohu, 201612.

Similar with Chl-a distribution, algal blooms mainly concentrated in east and west regions of the Lake Chaohu. They diffused and migrated continuously with changes of wind directions, temperature, total nitrogen and total phosphorus. Different from Chl-a, PC concentrated in the middle region of the Lake Chaohu in the beginning and then 
diffused toward two sides, migrating to the west region to a large scale. PC concentrated in center of the Lake Chaohu at about December 22nd, which conformed to the broken lines of daily average concentration in Fig.7 and spatial-temporal changes of concentration in Fig.9. Generally speaking, the daily average PC concentration in west region is the highest $(48.199 \mu \mathrm{g} / \mathrm{L}-77.228 \mu \mathrm{g} / \mathrm{L})$, followed by the east region $(41.014 \mu \mathrm{g} / \mathrm{L}-73.775 \mu \mathrm{g} / \mathrm{L})$ and the middle region $(46.184 \mu \mathrm{g} / \mathrm{L}-73.409 \mu \mathrm{g} / \mathrm{L})$. Due to continuous diffusion and migration, the PC concentration approaches to similar. The variation trend of PC concentration is highly similar with variation trend of temperature. There's still some difference. This is because wind direction and wind speed are important factors that influence clustering and migration of PC. However, these two parameters are not considered in this experiment.
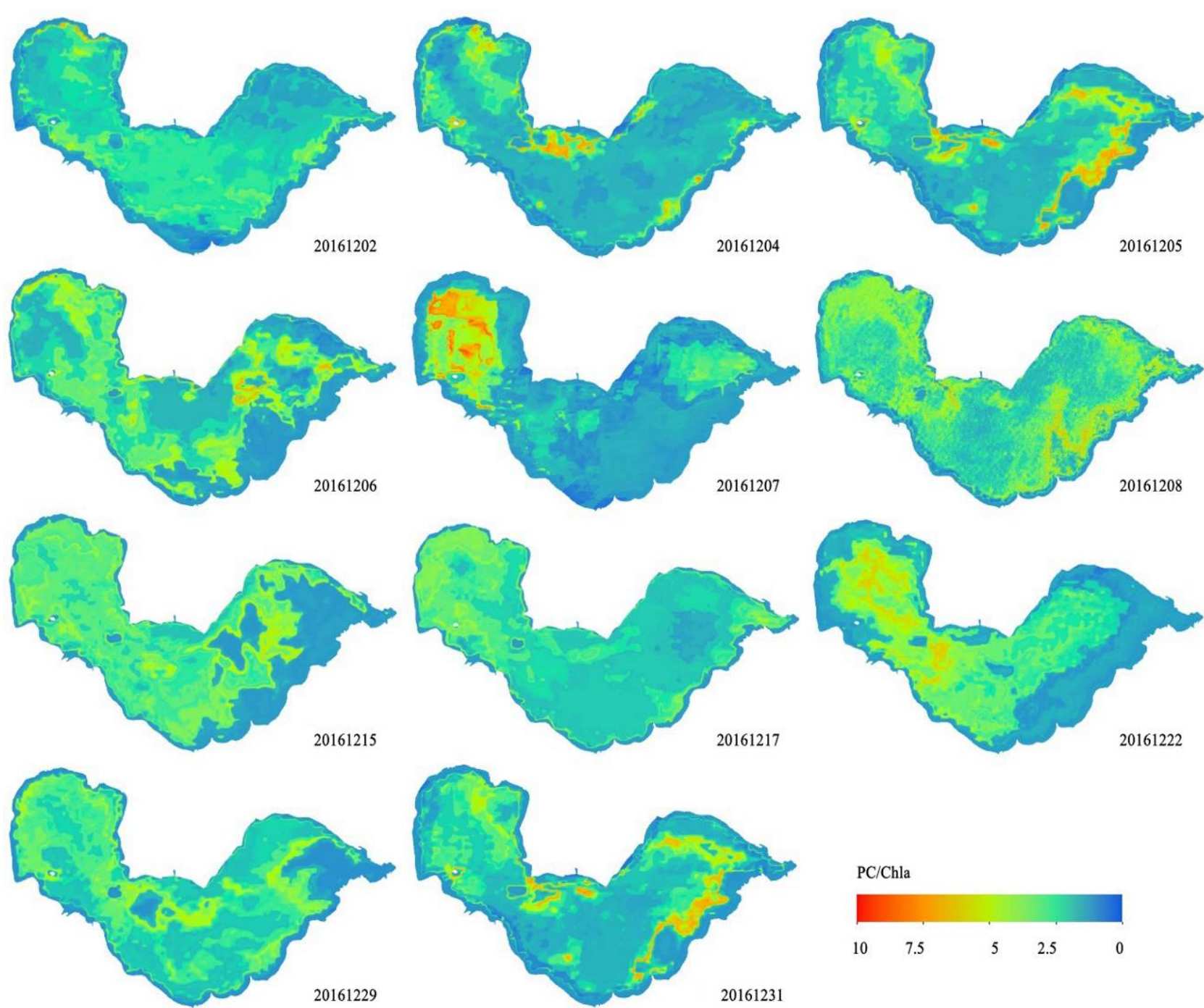

Fig. 11. Daily continuous PC:Chl-a images of Chaohu ,201612.

\subsection{Experiments on real-world networks}

Many studies have not only proved necessity of cyanobacteria bloom risk assessment in water head, but also provided an effective assessment method. Previous studies showed that PC: Chl-a product was derived from the inversion product of Chl-a concentration and the inversion product of PC concentration. This reflected proportion of PC biomass in aquatic biomass. Although the correlation between Chl-a concentration and PC concentration is very high, many studies have reflected difference between them. This is because Chl-a concentration reflects aquatic vegetation, cyanobacteria and other algae. Among them, only cyanobacteria may produce harmful substances to pollute water sources. Once the microcystic toxins (MCs) discharged during the growth of cyanobacteria are dissolved in water and then taken by human and animals, it will cause chronic toxicity. The Lake Chaohu is the major water source of surrounding cities. Therefore, it is very important to make continuous monitoring on cyanobacterial blooms and proportions in the Lake Chaohu.

According to cyanobacterial bloom risk spectra derived from the continuous monitoring product on December, 2016 (Fig.10) and daily average $\mathrm{PC}: \mathrm{Chl}$-a ratio in three regions of the Lake Chaohu (Fig.7(c)), PC concentrated in the middle region in a large scale in the begging of December, which was consistent with Fig.9. Later, the large-scaled spatial distribution of cyanobacterial bloom as well as main diffusion and migration paths in Fig.10 are consistent with inversion mapping of cyanobacteria blooms in Fig.9. Generally, cyanobacteria blooms are in dormancy in winter. Therefore, the proportion of PC concentration in the Lake Chaohu was very low on December, 2016. The whole water environment is threatened by cyanobacteria slightly even though there are cyanobacteria, which is attributed to the 
self-purification of water ecological environment. The cyanobacteria bloom risk spectra derived by inversion products of Chl-a concentration and PC concentration can reflect the region with high $\mathrm{PC}$ proportion in aquatic biological environment intuitively. This provides effective assistances to control of cyanobacteria blooms and sampling point in water.

\section{Conclusions}

To realize high-accuracy monitoring over the complicated small-scaled inland water environment and increase inversion accuracy as well as spatial resolution of inversion products, a spatial-temporal-spectral fusion model was applied for fusion of multisource remote sensing images and a multi-index collaborative model was constructed by using the random forest algorithm. Accuracies of inversion models based on fusion image and MODIS image under the same conditions were compared. Meanwhile, inversion and analysis on daily cyanobacteria bloom concentration were implemented. Some major conclusions could be drawn:

(1) The spatial-temporal-spectral fusion algorithm can integrate multisource remote-sensing images effectively and maintain spectral information to increase spatial resolution of images.

(2) Increasing spatial resolution of source images which participate in inversion modeling can increase the inversion accuracy of models effectively.
(3) Increasing spatial resolution of source images can improve spatial scale of inversion products significantly, thus enabling to reflect spatial-temporal distribution and variation trend of cyanobacteria blooms more truly and thoroughly.

(4) Increasing spatial scale of images from the perspective of image source based on the image fusion algorithm is conducive to realize continuous high-accuracy inversion monitoring of the complicated small-scaled inland water environment effectively.

In this study, a spatial-temporal-spectral fusion model was used to increase spatial resolution of images from the image source, thus increasing quality of inversion products. It was proved as a feasible and effective method. Moreover, it solved the problem that inversion products based on coarse resolution images are inapplicable to inversion monitoring of small-scaled water environments due to low spatial resolution. Nevertheless, there are great spatial resolutions between ETM+ images and MODIS images. There are data missing about spectra of images, spatial information inheritance and repair during the fusion process. It can achieve better monitoring results by adding multispectral images (e.g. Sentinel) with spatial resolution ranging between ETM+ images and MODIS images.

This is an Open Access article distributed under the terms of the Creative Commons Attribution License

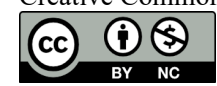

\section{References}

1. Han B P, "Reservoir ecology and limnology in China: a retrospective comment". Journal of Lake Sciences, 22(2), 2010, pp.151-160.

2. Kong F, Ma R, Gao J, et al, "The theory and practice of prevention, forecast and warning on cyanobacteria bloom in Lake Taihu". Journal of Lake Sciences, 3,2009, pp.314-328.

3. Reinart A, Kutser T, "Comparison of different satellite sensors in detecting cyanobacterial bloom events in the Baltic Sea". Remote Sensing of Environment, 102(1-2), 2006, pp.74-85.

4. Dall'Olmo G, Gitelson A A, Rundquist D C, "Towards a unified approach for remote estimation of chlorophyll - a in both terrestrial vegetation and turbid productive waters". Geophysical Research Letters, 30(18), 2003, pp.38-47.

5. Duan H T, Zhang S, Zhang Y, "Cyanobacteria bloom monitoring with remote sensing in Lake Taihu". Journal of Lake Sciences, 20(2), 2008, pp.145-152.

6. Jiang Y J, He W, Liu W X, et al, "The seasonal and spatial variations of phytoplankton community and their correlation with environmental factors in a large eutrophic Chinese lake (Lake Chaohu)". Ecological Indicators, 40, 2014, pp.58-67.

7. Dörnhöfer K, Klinger P, Heege T, et al, "Multi-sensor satellite and in situ monitoring of phytoplankton development in a eutrophicmesotrophic lake". Science of The Total Environment, 612, 2018, pp.1200-1214.

8. Liu X F, Duan H T, Ma R H, "The spatial heterogeneity of water quality variables in Lake Taihu". China. Journal of Lake Sciences, 22, 2010, pp.367-374.

9. LI Jian, TIAN Liqiao, CHEN Xiaoling, "Spatial Scale Uncertainties on Quantitative Remote Sensing of Water Qualities". Acta Geodaetica et Cartographica Sinica, 46(4), 2017, pp.478-486.

10. Bonansea M, Rodriguez M C, Pinotti L, et al, "Using multitemporal Landsat imagery and linear mixed models for assessing water quality parameters in Río Tercero reservoir (Argentina)". Remote Sensing of Environment, 158, 2015, pp.28-41.

11. Liu X F, Duan H T, Ma R H, "The spatial heterogeneity of water quality variables in Lake Taihu. China”. Journal of Lake Sciences, 22, 2010, pp.367-374.

12. $\mathrm{Hu} \mathrm{C}$, Lee $\mathrm{Z}$, Ma $\mathrm{R}$, et al., "Moderate resolution imaging spectroradiometer (MODIS) observations of cyanobacteria blooms in Taihu Lake, China". Journal of Geophysical Research: Oceans, 115(C4), 2010.
13. Shanmugam P, Suresh M, Sundarabalan B., "OSABT: An innovative algorithm to detect and characterize ocean surface algal blooms". IEEE Journal of Selected Topics in Applied Earth Observations and Remote Sensing, 6(4), 2012, pp.1879-1892.

14. Zhang Y, Ma R, Duan H, et al, "A novel algorithm to estimate algal bloom coverage to subpixel resolution in Lake Taihu". IEEE Journal of Selected Topics in Applied Earth Observations and Remote Sensing, 7(7), 2014, pp.3060-3068.

15. Qi L, Hu C, Duan H, et al, "A novel MERIS algorithm to derive cyanobacterial phycocyanin pigment concentrations in a eutrophic lake: Theoretical basis and practical considerations". Remote Sensing of Environment, 154, 2014, pp.298-317.

16. Gitelson A A, Dall'Olmo G, Moses W, et al, "A simple semianalytical model for remote estimation of chlorophyll-a in turbid waters: Validation". Remote Sensing of Environment, 112(9),2008, pp.3582-3593.

17. Moses W J, Gitelson A A, Berdnikov S, et al, "Estimation of chlorophyll-a concentration in case II waters using MODIS and MERIS data-successes and challenges". Environmental Research Letters, 4(4),2009,pp.045-055.

18. Gons H J., "Optical teledetection of chlorophyll a in turbid inland waters". Environmental Science \& Technology, 33(7),1999, pp.1127-1132.

19. Hu C, He M X., "Origin and offshore extent of floating algae in Olympic sailing area". Eos, Transactions American Geophysical Union, 89(33), 2008, pp.302-303.

20. $\mathrm{Hu} \mathrm{C}$, "A novel ocean color index to detect floating algae in the global oceans". Remote Sensing of Environment, 113(10), 2009, pp.2118-2129.

21. Shi W, Wang M, "Green macroalgae blooms in the Yellow Sea during the spring and summer of 2008". Journal of Geophysical Research: Oceans, 114(C12), 2009, pp.C12020.

22. Zhang Y, Ma R, Duan H, et al, "A novel MODIS algorithm to estimate chlorophyll a concentration in eutrophic turbid lakes". Ecological indicators, 69,2016, pp.138-151.

23. Deng D G, Xie P, Zhou Q, et al, "Studies on temporal and spatial variations of phytoplankton in Lake Chaohu". Journal of integrative plant biology, 49(4), 2007, pp. 409-418. 
24. Carvalho L, Miller C A, Scott E M, et al, "Cyanobacterial blooms: statistical models describing risk factors for national-scale lake assessment and lake management". Science of the Total Environment, 409(24), 2011, pp.5353-5358.

25. Fang $\mathrm{Xu}$, Duan Hongtao, Cao Zhigang, Shen Ming, Ge Xiaosan, "Remote monitoring of cyanobacterial blooms using multi-source satellite data: A case of Yuqiao Reservoir, Tianjin". Journal of Lake Sciences, 30(4), 2018, pp.967-978.

26. Liang Q, Zhang Y, Ma R, et al, “A MODIS-based novel method to distinguish surface cyanobacterial scums and aquatic macrophytes in Lake Taihu". Remote Sensing, 9(2), 2017, pp.133.

27. Duan H, Tao M, Loiselle S A, et al, "MODIS observations of cyanobacterial risks in a eutrophic lake: Implications for long-term safety evaluation in drinking-water source". Water Research, 122, 2017, pp.455-470.

28. $\mathrm{Xu} \mathrm{F}$, "Exergy and structural exergy as ecological indicators for the development state of the Lake Chaohu ecosystem". Ecological Modelling, 99(1), 1997, pp.41-49.

29. Kong X Z, Jørgensen S E, He W, et al, "Predicting the restoration effects by a structural dynamic approach in Lake Chaohu, China". Ecological modelling, 266, 2013, pp.73-85.

30. Zhang Y, Ma R, Zhang M, et al, "Fourteen-year record (2000-2013) of the spatial and temporal dynamics of floating algae blooms in Lake Chaohu, observed from time series of MODIS images". Remote Sensing, 7(8),2015, pp.10523-10542.

31. $\mathrm{Hu} \mathrm{C}$, Feng $\mathrm{L}$, Lee $\mathrm{Z}$, et al, "Dynamic range and sensitivity requirements of satellite ocean color sensors: learning from the past". Applied Optics, 51(25),2012, pp. 6045-6062.

32. $\mathrm{Hu} \mathrm{C}, \mathrm{He} \mathrm{M} \mathrm{X}$, "Origin and offshore extent of floating algae in Olympic sailing area”. Eos, Transactions American Geophysical Union, 89(33), 2008, pp. 302-303.

33. Meng X, Shen H, Zhang L, et al, "A unified framework for spatiotemporal-spectral fusion of remote sensing images". IEEE International Geoscience and Remote Sensing Symposium (IGARSS), 2015, pp.2584-2587.
34. Shen H, Meng X, Zhang L, "An integrated framework for the spatio-temporal-spectral fusion of remote sensing images". IEEE Transactions on Geoscience and Remote Sensing, 54(12), 2016, pp.7135-7148.

35. $\mathrm{Hu} \mathrm{C}$, "A novel ocean color index to detect floating algae in the global oceans". Remote Sensing of Environment, 113(10), 2009, pp.2118-2129.

36. Duan $\mathrm{H}, \mathrm{Ma} \mathrm{R}, \mathrm{Hu} \mathrm{C}$, "Evaluation of remote sensing algorithms for cyanobacterial pigment retrievals during spring bloom formation in several lakes of East China". Remote Sensing of Environment, 126, 2012, pp.126-135.

37. Duan H, Tao M, Loiselle S A, et al, "MODIS observations of cyanobacterial risks in a eutrophic lake: Implications for long-term safety evaluation in drinking-water source". Water Research, 122, 2017, pp.455-470.

38. Hunter P D, Tyler A N, Gilvear D J, et al, "Using remote sensing to aid the assessment of human health risks from blooms of potentially toxic cyanobacteria". Environmental Science \& Technology, 43(7), 2009, pp.2627-2633.

39. Edition F, "Guidelines for drinking-water quality". WHO chronicle, 38(4), 2011, pp.104-8.

40. Tyler A N, Hunter P D, Carvalho L, et al, "Strategies for monitoring and managing mass populations of toxic cyanobacteria in recreational waters: a multi-interdisciplinary approach". Environmental Health, 8(1),2009, pp.11.

41. Duan H, Tao M, Loiselle S A, et al, "MODIS observations of cyanobacterial risks in a eutrophic lake: Implications for long-term safety evaluation in drinking-water source". Water Research, 122, 2017, pp.455-470.

42. Shi K, Zhang Y, Li Y, et al, "Remote estimation of cyanobacteriadominance in inland waters". Water Research, 68, 2015, pp.217-22. 